\title{
Formatação de Feixe Oportunística para Sistemas OFDMA Sujeitos a Desvanecimento Lento
}

\author{
João Luiz Rebelatto, Bartolomeu F. Uchôa-Filho e Iuri R. Baran
}

\begin{abstract}
Resumo-Múltiplo acesso por divisão ortogonal em freqüiência (OFDMA) é uma técnica utilizada nos mais recentes sistemas de comunicação sem fio, como o IEEE 802.16e WiMax, e propícia para a exploração da diversidade multiusuário. Em canais com desvanecimento lento, para que os efeitos benéficos da diversidade multiusuário sejam obtidos, faz-se necessário induzir variações no canal, através do uso de múltiplas antenas transmissoras, por exemplo, esquema denominado de formatação de feixe oportunística. Neste trabalho, é proposta uma técnica de formatação de feixe oportunística para sistemas OFDMA, sujeitos a desvanecimento temporal lento. A técnica proposta utiliza uma memória no transmissor, contendo alguns coeficientes de formatação de feixe aleatórios. Simulações mostram que a escolha do melhor coeficiente presente na memória resulta em um aumento significativo na vazão total do sistema.
\end{abstract}

Palavras-Chave-OFDMA, diversidade multiusuário, formatação de feixe oportunística, múltiplas antenas.

Abstract-Orthogonal Frequency Division Multiple Access (OFDMA) is a technique adopted in the most recent wireless communication systems, such as the IEEE 802.16e WiMax, and is suitable for exploring multiuser diversity. In slow fading channels, in order to obtain the benefits of multiuser diversity, channel variations are artificially induced through the use of multiple antennas, by a transmission scheme called opportunistic beamforming. In this work, an opportunistic beamforming technique is proposed for OFDMA systems subjected to slow fading. The proposed technique utilizes a memory in the transmitter, which contains some pseudo-random beamforming coefficients. Computer simulations show that the adoption of the best coefficient present in the memory results in a significant improvement in the total system throughput.

Keywords-OFDMA, multiuser diversity, opportunistic beamforming, multiple antennas.

\section{INTRODUÇÃO}

A técnica de multiplexação por divisão ortogonal em frequiência (OFDM) vem sendo largamente utilizada nos sistemas de comunicação atuais, devido a sua robustez à interferência intersimbólica causada pelo canal. A versão multiusuário dessa técnica, o Múltiplo Acesso por Divisão Ortogonal em Frequiência (OFDMA), permite que durante um mesmo slot de tempo (TS, do inglês time slot), os subcanais (subportadoras) sejam alocados para usuários distintos, possibilitando que seja explorada a diversidade de multiusuário.

Trabalhos recentes têm enfatizado a importância da diversidade multiusuário no aumento da vazão (throughput) total de redes de dados sem fio. Knopp e Humblet [1] mostraram que se as estações móveis (EM) são capazes de estimar a situação

João Luiz Rebelatto, Bartolomeu F. Uchôa-Filho e Iuri R. Baran, GPqCom, EEL, Universidade Federal de Santa Catarina, Florianópolis, Brasil, E-mails: joaoluiz@eletrica.eng.br, uchoa@eel.ufsc.br, iuri.baran@gmail.com. Este trabalho foi parcialmente financiado pelo CNPq (131684/2007-8, 484391/2006-2 e 303938/2007-2) instantânea de seus canais, indicadas pelas suas relaçõessinal-ruído (SNRs), e enviam estas para a estação rádio-base (ERB), a estratégia que maximiza a capacidade teórica total de informação do sistema é alocar todos os recursos de banda disponível para o usuário com melhor canal naquele TS. O ganho obtido através da diversidade multiusuário vem do fato de que em um sistema com vários usuários, as condições dos canais de cada usuário variam independentemente umas das outras. Conseqüentemente, é bem provável que em um instante de tempo, o escalonador presente na ERB encontrará pelo menos um usuário cujo canal se encontre em condições favoráveis para a transmissão.

Porém, em canais quase-estáticos, essa técnica não apresenta bons resultados, pois a variação do canal ocorre de maneira lenta, e dentro de uma faixa dinâmica pequena. Com o intuito de gerar uma variação artificial no canal, Viswanath et.al. [2] propuseram o uso de múltiplas antenas convencionais no transmissor, todas transmitindo a mesma informação ao mesmo tempo, porém, sujeitas a coeficientes de formatação (ganhos e fases) pseudo-aleatórios, esquema este denominado formatação de feixe oportunística (OBF). No esquema OBF, as múltiplas antenas são completamente transparentes ao receptor.

Em [3], considera-se que o canal possui alta coerência temporal (variação lenta) e propõe-se a utilização de uma memória no transmissor, para que sejam armazenados os últimos coeficientes de formatação utilizados, juntamente com a taxa suportada pelo canal composto. Após a escolha do usuário para quem se irá transmitir, considera-se para a transmissão o coeficiente gerador da melhor taxa, porém, necessitase de uma nova estimação do canal no receptor. Essa técnica foi denominada formatação de feixe oportunística coerente no tempo (TC-OBF). As idéias apresentadas em [1], [2] e [3] podem ser estendidas para o domínio da freqüência, ou seja, os usuários seriam selecionados em seus picos de desvanecimento nesse outro domínio, em cada subportadora.

Em [4], os autores propuseram um esquema de diversidade multiusuário na frequiência em que as células são divididas em setores, através da utilização de coeficientes de formatação ortogonais (beams). Tal esquema possibilita que cada subportadora seja capaz de acomodar mais de um usuário ao mesmo tempo, porém, utilizando uma quantidade maior de graus de liberdade e de sinais piloto, se comparado com o esquema proposto neste trabalho, o TC-OBF-OFDMA.

Além do interesse em aumentar a capacidade do sistema, deve-se tomar cuidado em realizar uma divisão justa dos recursos do canal entre os diversos usuários, como também em evitar que um usuário específico fique muito tempo sem receber informação, situação que pode comprometer a transmissão, 
dependendo da aplicação. Um algoritmo de escalonamento oportunístico bem conhecido, denominado escalonamento proporcional justo (PFS), oferece um compromisso entre vazão e justiça.

Neste trabalho é proposta uma técnica para aumentar a capacidade de transmissão de sistemas OFDMA, explorando a coerência temporal do canal através da escolha do melhor coeficiente de formatação disponível.

Assim como o TC-OBF-OFDMA, o esquema proposto em [4] explora a correlação temporal para aumentar a vazão total do sistema. Entretanto, isso se dá de maneira totalmente diferente daquela proposta neste artigo. Primeiramente, o conceito de beams em [4] é semelhante ao conceito de pipes em [5], e não tem nenhuma relação com a exploração da correlação temporal. O benefício extraído da correlação temporal em [4] se restringe à manutenção de alguns coeficientes de formatação de feixe, aqueles associados às melhores taxas, nos melhores beams, de um bloco de símbolos OFDM para o próximo. No esquema proposto neste trabalho, múltiplas transmissões de símbolos OFDM piloto são realizadas, com coeficientes de formatação de feixe distintos, no início do bloco de coerência. Os melhores coeficientes de formatação de feixe são então selecionados para transmissão de dados no restante dos símbolos OFDM do bloco de coerência. Essa ação resulta em um ganho de diversidade de combinação de seleção que, em adição ao ganho de diversidade de multiusuário já presente na formatação de feixe oportunística, gera ganhos de vazão que não são obtidos com a técnica proposta em [5], uma vez que em [5] há a transmissão de apenas um único símbolo OFDM piloto por bloco.

A organização deste artigo é como se segue. Na seção II são apresentados os esquemas OBF [2], PFS, TC-OBF [3], como descritos originalmente nessas referências, porém adaptados ao OFDMA. A Seção III apresenta a descrição do esquema proposto, o TC-OBF-OFDMA. Na seção IV, são expostos alguns resultados de simulações, que exibem a eficiência da nova técnica. Por fim, a seção V apresenta as conclusões e comentários finais.

\section{Preliminares}

\section{A. Formatação de Feixe Oportunística $(\mathrm{OBF})$}

$\mathrm{O}$ esquema de formatação de feixe oportunístico utilizado neste trabalho considera um modelo básico de canal direto em uma rede de dados sem fio, com OFDMA. Nesse sistema de transmissão complexo em banda básica, omitindo-se o índice do tempo e desprezando-se possíveis interferências de células co-canal, o sinal recebido pelo $k$-ésimo usuário, na $n$-ésima subportadora, será:

$$
y_{n, k}=\mathbf{h}_{n, k}^{T} \mathbf{b}_{n} \sqrt{P} x_{n}+z_{n, k},
$$

onde $x_{n}$ é o símbolo de energia unitário transmitido na $n$ ésima subportadora, $z_{n, k}$ é o ruído aditivo Gaussiano complexo com variância $\sigma_{z}^{2}$ no receptor do $k$-ésimo usuário e referente à $n$-ésima subportadora, $\mathbf{h}_{n, k} \in \mathbb{C}^{M_{t} \times 1}$ é o vetor de resposta em frequiência em banda básica das $M_{t}$ antenas transmissoras para o $k$-ésimo usuário na $n$-ésima subportadora. $\mathbf{b}_{n} \in \mathbb{C}^{M_{t} \times 1}$ é o vetor de coeficientes de formatação para a $n$-ésima subportadora e $P$ é a potência transmitida por subportadora. Os elementos de $\mathbf{b}_{n}$ são variáveis complexas i.i.d. com fase e magnitude uniformemente distribuídas em $[0,2 \pi)$ e $[0,1)$, respectivamente, e normalizadas de tal forma que $\left\|\mathbf{b}_{n}\right\|=1$. Considerando-se $H_{n, k}=\mathbf{h}_{n, k}^{T} \mathbf{b}_{n}$ a resposta em freqüência complexa efetiva (canal composto equivalente) da estação base para o usuário $k$ na subportadora $n$, tem-se:

$$
y_{n, k}=H_{n, k} \sqrt{P} x_{n}+z_{n, k} .
$$

Focando em um usuário $k$ particular, seu vetor de coeficientes de formatação $\mathbf{b}_{n}$ varia em todas as direções, ou seja, o módulo $\left|H_{n, k}\right|^{2}$ do canal composto visto pelo usuário $k$, na $n$-ésima portadora, varia de 0 até $\left[\sum_{l=0}^{M_{t}}\left|h_{n, k, l} b_{n, l}\right|\right]^{2}$. O seu valor de pico ocorre quando a formatação na transmissão está alinhada na direção do canal do usuário $k$, ou seja, $\mathbf{b}_{n}=\mathbf{h}_{n, k} /\left\|\mathbf{h}_{n, k}\right\|$. Quando isso ocorre, diz-se que o usuário está em sua configuração de formatação de feixe ótima.

Vale ressaltar que a utilização de múltiplas antenas é completamente transparente aos usuários, e tem como objetivo apenas aumentar a taxa de desvanecimento na freqüência, sendo uma extensão direta da idéia em [2] e [3], onde diferentes coeficientes de formatação são usados em diferentes blocos de transmissão para aumentar a taxa de desvanecimento temporal.

\section{B. Escalonamento Proporcional Justo (PFS)}

De acordo com [1], transmitir para o usuário com canal instantâneo em melhores condições maximiza a vazão total do sistema, porém, essa estratégia pode ser injusta com os usuários que por algum motivo (distância maior da ERB, por exemplo) estejam com seus canais em condições menos favoráveis por um longo intervalo de tempo. O algoritmo PFS provê uma relação de compromisso entre ganho de diversidade multiusuário, justiça e atraso. Cada usuário móvel estima as condições do seu próprio canal e informa para a ERB. Na ERB, um algoritmo PFS independente agirá em cada subportadora. O algoritmo PFS na subportadora $n$ irá alocar os recursos do canal para o usuário $k_{n}^{*}$, determinado como:

$$
k_{n}^{*}=\arg \max _{k \in\{1,2, \ldots, K\}} \frac{R_{n, k}(t)}{T_{k}(t)},
$$

onde $R_{n, k}(t)$ é a máxima taxa instantânea suportada pelo usuário $k$ na subportadora $n$ no TS $t$, e $K$ é o número de usuários. Essa taxa é uma função da relação sinal-ruído (SNR) dos usuários, tipicamente $\log _{2}(1+\mathrm{SNR}) . T_{k}(t)$ denota a vazão média atual do $k$-ésimo usuário, considerando-se uma janela temporal de comprimento $t_{c}$, atualizada a cada TS como se segue:

$$
T_{k}(t+1)=\left(1-\frac{1}{t_{c}}\right) T_{k}(t)+\frac{1}{t_{c}}\left(\sum_{n=1}^{N_{c}} J_{n, k}(t) R_{n, k}(t)\right),
$$

onde $N_{c}$ é o número de subportadoras e $J_{n, k}(t)$ é uma função indicadora que informa quais as subportadoras que o $k$-ésimo usuário está utilizando no TS $t$, ou seja, $J_{n, k}(t)=1$ se $k=k_{n}^{*}$ e $J_{n, k}(t)=0$ se $k \neq k_{n}^{*}$. 
Com a seleção dos usuários em cada subportadora baseada em (3), o PFS aumenta a capacidade do sistema e ao mesmo tempo mantém justiça, pois seleciona usuários com alta taxa instantânea, $R_{n, k}(t)$, ou baixa vazão média, $T_{k}(t)$, no caso de ficarem muito tempo sem serem servidos.

O parâmetro $t_{c}$ está relacionado com a latência da aplicação e possibilita um compromisso entre ganho de diversidade multiusuário e atraso de escalonamento. Se $t_{c}$ for grande (tendendo ao infinito), o algoritmo PFS tenderá a selecionar o usuário com o melhor canal instantâneo, não se importando com a justiça. Entretanto, se $t_{c}$ for pequeno (perto de 1), os usuários não poderão esperar muito tempo sem serem escalonados, e talvez ocorra de serem escalonados quando sua taxa suportada não seja realmente alta.

\section{Formatação de Feixe Oportunística com Coerência Tem- poral (TC-OBF)}

$\mathrm{O}$ esquema TC-OBF explora o tempo em que o canal de comunicação se mantém fortemente correlacionado (tempo de coerência) para providenciar um aumento no desempenho do sistema em termos da vazão média do canal. No TC-OBF, a cada TS, os coeficientes de formatação de feixe juntamente com as correspondentes SNRs (ou taxas de transmissão suportadas) de cada usuário são gravados em uma memória na ERB. O tamanho da memória ( $M_{s}$, em slots de tempo) é relacionado com o tempo de coerência do canal. Através do PFS, a ERB seleciona o usuário (de índice $k_{n}^{*}$ ) com o maior $R_{n, k}(t) / T_{k}(t)$. Os coeficientes de formatação de feixe nesse momento, para cada subportadora, são obtidos aleatória e independentemente. A SNR desse usuário é descrita como $\mathrm{SNR}_{k_{n}^{*}}$. Nesse instante, o algoritmo TC-OBF procura o vetor de coeficientes de formatação de feixe $\mathbf{b}_{n}^{\prime}(t)$ que corresponda à máxima SNR ponderada, isso é, o máximo produto da SNR na memória para o usuário $k_{n}^{*}$ e um fator de esquecimento $\omega(\tau)(0$ a 1$)$, o qual diminui à medida que $\tau$ aumenta, onde $\tau$ é a diferença entre o tempo da medida e o tempo atual, medido em slots de tempo. Seja $\operatorname{SNR}_{k_{n}^{*}}(t-\tau)$ a SNR do usuário $k_{n}^{*}$ armazenada na memória há $\tau$ slots de tempo. Então, o novo vetor de coeficientes de formatação de feixe a ser usado na transmissão é dado por $\mathbf{b}_{n}^{\prime}(t)=\mathbf{b}_{n}\left(t-\tau_{k_{n}}^{*}\right)$, onde:

$$
\tau_{k_{n}^{*}}=\arg \max _{\tau \in\{0,1, \ldots, M S-1\}} S N R_{k_{n}^{*}}(t-\tau) \omega(\tau) .
$$

Para o canal com desvanecimento em bloco (quase-estático), $\omega(\tau)$ deve ser unitário durante todo o bloco de coerência.

\section{Múltiplo Acesso por Divisão Ortogonal em Freqüência (OFDMA)}

Múltiplo Acesso por Divisão Ortogonal em Frequiência (OFDMA) é uma versão multiusuário do popular esquema de modulação digital OFDM. Esse esquema pode proporcionar altas taxas de dados, aumentando a robustez contra interferência e a eficiência na utilização de recursos, tais como banda e potência de transmissão. OFDMA permite que as portadoras sejam vistas como canais independentes, comportando vários usuários ao mesmo tempo e permitindo que a diversidade multiusuário possa ser explorada.
Devido a essas vantagens promissoras, OFDMA é empregado em vários padrões internacionais, por exemplo, IEEE 802.16 WiMAX [6], 3GPP Long Term Evolution (LTE) [7] e High Speed OFDM Packet Access (HSOPA) [8]. Além disso, OFDMA é um método de acesso candidato para o padrão IEEE 802.22 Wireless Regional Area Networks [9]. OFDMA tem sido visto como uma das mais promissoras tecnologias de acesso para as redes sem fio atuais e futuras.

A idéia básica desta técnica de modulação com multiportadoras é dividir a banda disponível em vários subcanais com banda menor (subportadoras), ortogonais entre si. O número total de subportadoras é escolhido de forma a assegurar que cada uma tenha uma largura de banda menor que a banda de coerência do canal, assim sendo, cada subportadora está sujeita a desvanecimento aproximadamente plano, tornando a interferência intersimbólica (ISI) em cada canal pequena. Através do uso do prefixo cíclico, a ISI pode ser completamente eliminada.

\section{TC-OBF COM OFDMA}

No padrão IEEE 802.16e [6], a largura de banda especificada varia na faixa de $1,25 \mathrm{MHz}$ a $20 \mathrm{MHz}$, e o número de subportadoras, $N_{c}$, de 128 a 2048. Em [10], é apresentado um exemplo onde a banda de freqüência disponível é 2-6 GHz e a velocidade do usuário móvel é $125 \mathrm{Km} / \mathrm{h}$ (a maior com a qual o sistema consegue lidar). Para esses parâmetros, o tempo de coerência seria $T_{c}=1,03 \mathrm{~ms}$. Como o símbolo OFDMA (ou seja, um TS) tem duração de $108 \mu$ s [10], temos um bloco de aproximadamente 10 símbolos OFDMA com alta correlação no canal. Para velocidades baixas (por exemplo, $3 \mathrm{Km} / \mathrm{h}$ ), esse bloco poderia exceder 400 símbolos OFDMA sem que as alterações no canal sejam significativas.

Como visto anteriormente, para que seja obtido o ganho de diversidade multiusuário, a taxa e a faixa dinâmica de variação do canal devem ser altas. Assim como o OBF [2], TC-OBF [3] faz com que essa variação seja aumentada, porém, essas técnicas foram desenvolvidas para sistemas de portadora única. Uma vez quem em OFDM e OFDMA os sinais piloto são acomodados no domínio da freqüência, não haveria a possibilidade de transmissão de uma outra configuração de formatação de feixe durante um mesmo slot de tempo. Dessa forma, a técnica proposta, TC-OBF-OFDMA, utiliza os primeiros $M_{s}$ slots de tempo de cada bloco de símbolos OFDMA para a transmissão de pilotos com diferentes coeficientes de formatação de feixe, armazenando-os em uma memória. Após esses $M_{s}$ slots de tempo, a ERB seleciona da memória os coeficientes que resultaram na melhor taxa em cada subportadora, e os utiliza durante todo o restante do bloco de coerência. Conforme exposto na seção II-C, como o canal é considerado quase-estático, o fator de esquecimento $\omega(\tau)$ é igual a 1 durante todo os $M_{s}$ slots de tempo.

Na seqüência está apresentado o TC-OBF-OFDMA:

1) Durante os $M_{s}$ slots de tempo iniciais de cada bloco de coerência, a ERB transmite $M_{s}$ símbolos OFDMA contendo apenas sinais piloto em todas as subportadoras. Esses sinais são formatados com diferentes coeficientes (pseudo-aleatórios) de formatação, $\mathbf{b}_{n}(t)$, onde $t=$ 
$1, \ldots, M_{s}$ indica os slots de tempo de memória e $n \in$ $\left\{1, \ldots, N_{c}\right\}$ a $n$-ésima subportadora;

2) Os usuários estimam as taxas suportadas em cada subportadora $n$, para cada uma das $M_{s}$ possibilidades de coeficientes de formatação, i.e., para $t=1, \ldots, M_{s}$, e retornam esses valores para a ERB;

3) Após receber os valores, a ERB seleciona, para a $n$-ésina subportadora, o usuário $k_{n}^{*}$ (com a maior taxa requerida, $R_{n, k_{n}^{*}}^{\prime}(t)$ ), escolhido da seguinte maneira:

$$
k_{n}^{*}=\arg \max _{k \in\{1, \ldots, K\}} \max _{t \in\left\{1, \ldots, M_{s}\right\}} \frac{R_{n, k}(t)}{T_{k}(t)},
$$

e passa a adotar na $n$-ésima subportadora o coeficiente de formatação $\mathbf{b}_{n}^{\prime}(t)$ que gerou a maior taxa, durante todo o bloco de coerência;

4) No TS seguinte, são enviados pilotos para que todos os usuários saibam qual a configuração de formatação que está sendo utilizada;

5) A partir do TS de índice $M_{s}+2$ é realizada a transmissão de dados de acordo com o algoritmo $\mathrm{PFS}^{1}$, até que se encerre o bloco de coerência;

6) A seguir, inicia-se novamente o procedimento, retornando para o item 1.

Para se determinar o tamanho da memória $M_{s}$, deve-se considerar alguns fatores: Primeiro, se o seu valor for muito grande, haverá um grande desperdício de slots de tempo com a transmissão somente de pilotos, reduzindo a vazão média total. Segundo, se for muito pequeno, aumenta a probabilidade de nenhum dos coeficientes de formatação "sorteados" resultar em um ganho considerável. Terceiro, o ganho obtido na passagem de $M_{s}=1$ para $M_{s}=2$ é maior que o obtido na passagem de $M_{s}=2$ para $M_{s}=3$, e assim por diante, até que em um ponto, na passagem de $M_{s}=M_{s}^{*}$ para $M_{s}=M_{s}^{*}+1$, o valor da vazão média total diminuirá, devido ao grande desperdício já citado. Ou seja, há um valor ótimo $M_{s}^{*}$ de tamanho de memória.

O valor ótimo para o tamanho da memória depende da seletividade em frequiência do canal e da quantidade de usuários no sistema. Quanto mais seletivo for o canal, menor é o valor de $M_{s}^{*}$, pois a variação natural (e em larga escala) do desvanecimento em freqüência de um usuário para o outro se encarregará de fornecer as condições necessárias para que seja obtido o ganho de diversidade multiusuário. $\mathrm{O}$ mesmo ocorre à medida em que o número de usuários $K$ do sistema aumenta.

$\mathrm{Na}$ seqüência, são apresentados alguns resultados de simulações computacionais que visam ilustrar o exposto nesta seção.

\section{Resultados das Simulações}

Nas simulações foi considerado um canal quase-estático, com perfis de potência apresentados na Tabela I, correspondentes aos modelos de canais da Universidade de Stanford (SUI) [10]. No que diz respeito ao tipo de região geográfica que esses modelos representam, os canais SUI 1-2 modelam uma

\footnotetext{
${ }^{1}$ Note que é possível, se o PFS assim determinar, que os recursos do canal sejam alocados para usuários diferentes durante um mesmo bloco de coerência.
}

região plana e com pequena densidade de obstáculos, enquanto os canais SUI 3-4 representam uma região montanhosa e com pequena ou média densidade, ou plana com grande densidade. Já os canais SUI 5-6 correspondem a regiões montanhosas e com média ou grande densidade.

TABELA I

PERFIL DE POTÊNCIA DOS CANAIS SUI 1-6.

\begin{tabular}{|c|c|c|c|c|}
\hline SUI - 1 & Atrasos $(\mu \mathrm{s})$ & 0 & 0,4 & 0,9 \\
\cline { 2 - 5 } & Ganho $(\mathrm{dB})$ & 0 & -15 & -20 \\
\hline SUI - 2 & Atrasos $(\mu \mathrm{s})$ & 0 & 0,4 & 1,1 \\
\cline { 2 - 5 } & Ganho $(\mathrm{dB})$ & 0 & -12 & -15 \\
\hline SUI - 3 & Atrasos $(\mu \mathrm{s})$ & 0 & 0,4 & 0,9 \\
\cline { 2 - 5 } & Ganho $(\mathrm{dB})$ & 0 & -5 & -10 \\
\hline SUI - 4 & Atrasos $(\mu \mathrm{s})$ & 0 & 1,5 & 4 \\
\cline { 2 - 5 } & Ganho $(\mathrm{dB})$ & 0 & -4 & -9 \\
\hline SUI - 5 & Atrasos $(\mu \mathrm{s})$ & 0 & 4 & 10 \\
\cline { 2 - 5 } & Ganho $(\mathrm{dB})$ & 0 & -5 & -10 \\
\hline SUI - 6 & Atrasos $(\mu \mathrm{s})$ & 0 & 14 & 20 \\
\cline { 2 - 5 } & Ganho $(\mathrm{dB})$ & 0 & -10 & -14 \\
\hline
\end{tabular}

Foi feita a consideração de que os usuários estão uniformemente distribuídos na área de cobertura, e que possuem SNR média de $0 \mathrm{~dB}$. É suposto também que as subportadoras têm espaçamento constante, independente da largura de banda do canal.

A técnica TC-OBF-OFDMA foi comparada com o esquema sem utilização de formatação de feixe oportunística (utilização de somente uma antena) e com o esquema de formatação de feixe ótima, conforme descrito na Seção II-A.

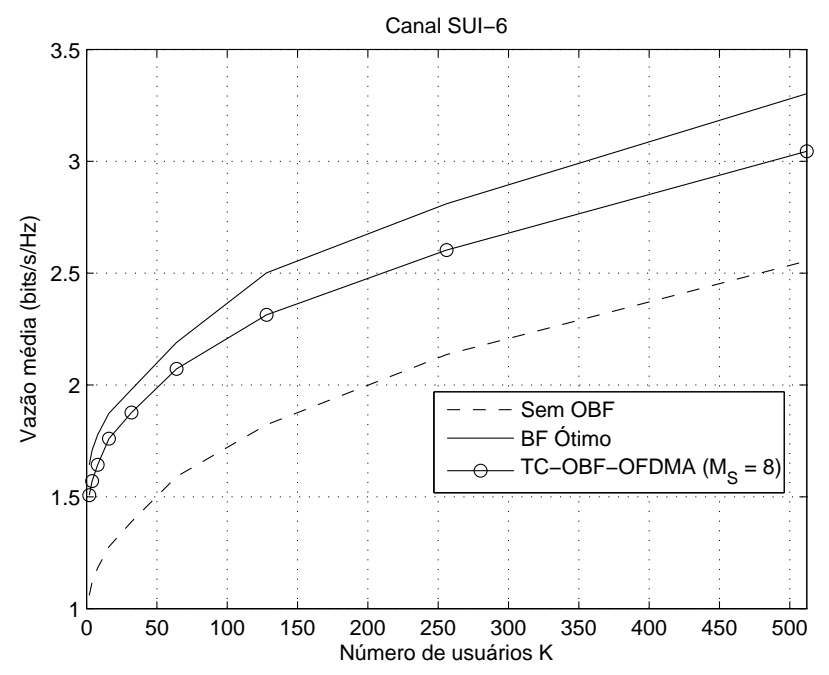

Fig. 1. Vazão média (bits/s/Hz) em função do número de usuários $K$, para um sistema com $N_{c}=128$ subportadoras, tamanho de memória $M=8$, tempo de latência $t_{c} \longrightarrow \infty$ e usuários com velocidade de $3 \mathrm{Km} / \mathrm{h}$, considerando-se o modelo de canal SUI-6.

A Figura 1 apresenta a vazão média total do sistema (em bits/s/Hz) em função do número de usuários $K$, considerandose uma janela de $t_{c} \longrightarrow \infty$ para o PFS, $M_{s}=8$ slots de tempo, $N_{c}=128$ subportadoras e canal com perfil de potência descrito pelo modelo SUI - 6, com alta correlação temporal (velocidade dos usuários móveis de $3 \mathrm{Km} / \mathrm{h}$ ). Percebe-se que a vazão média obtida com o esquema TC-OBF-OFDMA apre- 
senta um grande incremento se comparada ao esquema sem formatação de feixe, ficando muito próximo da formatação de feixe ótima.

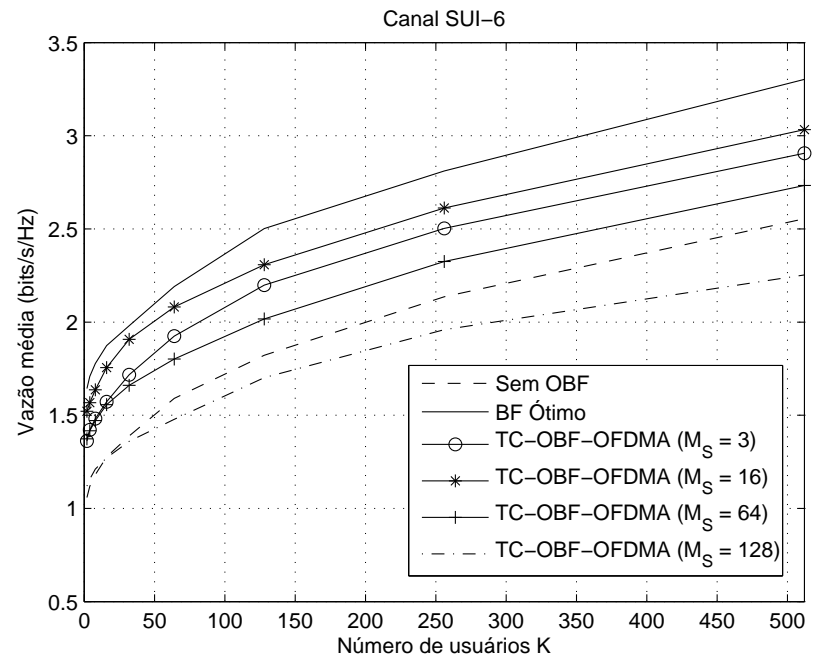

Fig. 2. Vazão média (bits/s/Hz) em função do número de usuários $K$, para um sistema com $N_{c}=128$ subportadoras, tempo de latência $t_{c} \longrightarrow \infty$, modelo de canal SUI-6, usuários com velocidade de $3 \mathrm{Km} / \mathrm{h}$, considerando-se os três esquemas de transmissão: Sem formatação de feixe, com formatação ótima de feixe e TC-OBFOFDMA com $M_{s}=\{3,16,64$ e 128$\}$.

Na Figura 2 estão contidos os mesmos três esquemas de transmissão da Figura 1, porém, são traçadas as curvas do TC-OBF-OFDMA para os valores de $M_{s}=\{3,16,64$ e 128 $\}$. Percebe-se que o aumento de $M_{s}=3$ para $M_{s}=16$ apresenta um incremento na vazão média, porém, ao passar para o valor de $M_{s}=64$ slots de tempo, há uma grande queda no valor da vazão, e considerando $M_{s}=128$, o resultado torna-se pior que o caso sem nenhum esquema de formatação, pois o desperdício de slots de tempo para a transmissão de pilotos é muito grande.

A Figura 3 apresenta a vazão média total do sistema em função do tamanho da memória $M_{s}$, considerando dois perfis de potência distintos, com espalhamentos de atraso rms 0,534 ms (Canal hipotético A, mais seletivo, com atrasos e ganhos iguais a $\{00,140,20\} \mathrm{ms}$ e $\{0-10-14\} \mathrm{dB}$, respectivamente) e $0,11 \mu$ s (Canal SUI-1, menos seletivo), e uma quantidade de $K=256$ usuários, $N_{c}=128$ subportadoras e $t_{c} \longrightarrow \infty$. Nota-se que o valor ótimo $M_{s}^{*}$ do tamanho da memória varia de acordo com o perfil de potência (seletividade) dos canais. Para o canal A, por exemplo, este valor ótimo é próximo a $M_{s}=8$ slots de tempo, já para o canal SUI-1, próximo a $M_{s}=16$ slots de tempo. Para uma melhor visualização, os valores do Gráfico 3 estão apresentados na Tabela II.

A análise do desempenho do esquema proposto no caso em que $t_{c}$ não tende ao infinito (justiça em troca de vazão está apresentada na Figura 4. Percebe-se que o esquema TC-OBFOFDMA apresenta uma melhora considerável se comparado ao esquema sem formatação.

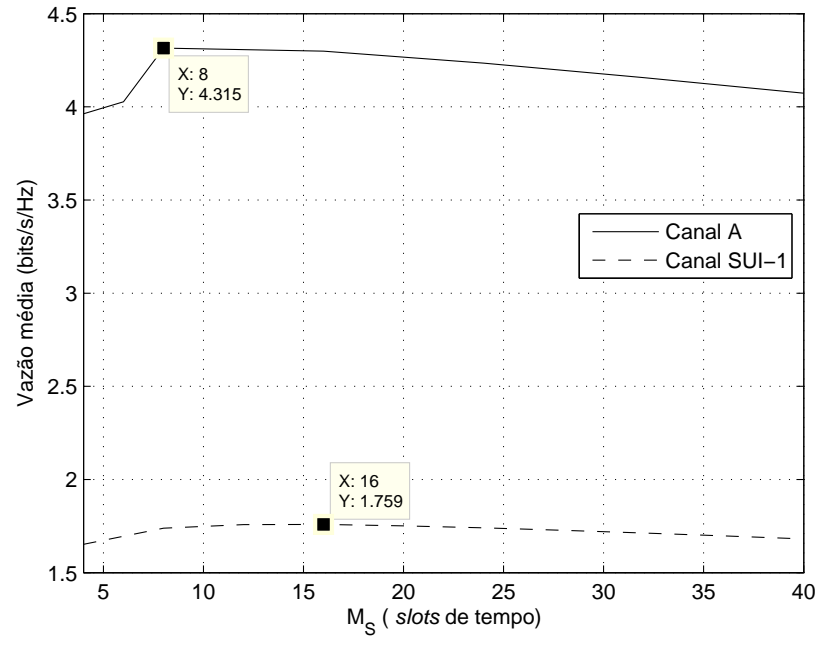

Fig. 3. Vazão média (bits/s/Hz) em função do tamanho do tamanho da memória $M_{s}$, para um sistema com $N_{c}=128$ subportadoras, tempo de latência $t_{c} \longrightarrow \infty, K=256$ usuários, usuários com velocidade de $3 \mathrm{Km} / \mathrm{h}$, considerando-se os modelos de canal A e SUI-1.

TABELA II

VAZÃO EM FUNÇÃO DO TAMANHO DA MEMÓRIA.

\begin{tabular}{|c|c|c|c|}
\hline \multicolumn{2}{|c|}{ Canal A } & \multicolumn{2}{c|}{ Canal SUI-1 } \\
\hline $\begin{array}{c}M_{s} \\
\text { (TS) }\end{array}$ & $\begin{array}{c}\text { Vazão } \\
\text { (bits/s/Hz) }\end{array}$ & $\begin{array}{c}M_{s} \\
\text { (TS) }\end{array}$ & $\begin{array}{c}\text { Vazão } \\
\text { (bits/s/Hz) }\end{array}$ \\
\hline 4 & 3,9623 & 4 & 1,6518 \\
\hline $\mathbf{8}$ & $\mathbf{4 , 3 1 5 3}$ & 8 & 1,7386 \\
\hline 16 & 4,2992 & $\mathbf{1 6}$ & $\mathbf{1 , 7 5 8 9}$ \\
\hline 24 & 4,2340 & 24 & 1,7403 \\
\hline 32 & 4,1563 & 32 & 1,7126 \\
\hline 40 & 4,0731 & 40 & 1,6806 \\
\hline
\end{tabular}

\section{Conclusões}

Uma forma de aumentar a vazão média de sistemas OFDMA em canais com variação lenta foi proposta. O novo esquema utiliza uma memória no transmissor (estação rádio-base), na qual são armazenados alguns coeficientes de formatação de feixe oportunísticos, juntamente com a taxa suportada pelo canal composto de cada usuário, em cada subportadora. Simulações mostraram que a escolha do melhor coeficiente dentre os presentes na memória e a manutenção do mesmo por todo o bloco de coerência do canal pode gerar um grande aumento na vazão média do sistema, aproximando-se da formatação ótima.

Mostrou-se também que o tamanho da memória, $M_{s}$, possui um valor ótimo, e que esse valor depende do canal e da quantidade de usuários do sistema.

$\mathrm{Na}$ sequiência do trabalho, será realizado um estudo do atraso de escalonamento entre os usuários, bem como a consideração de um canal com desvanecimento variante no tempo e correlacionado, ao invés de desvanecimento em bloco.

\section{REFERÊNCIAS}

[1] R. Knopp e P. Humblet, "Information capacity and power control in single cell multiuser communication," IEEE ICC'95, v. 1, pp. 331-335, Junho 1995. 


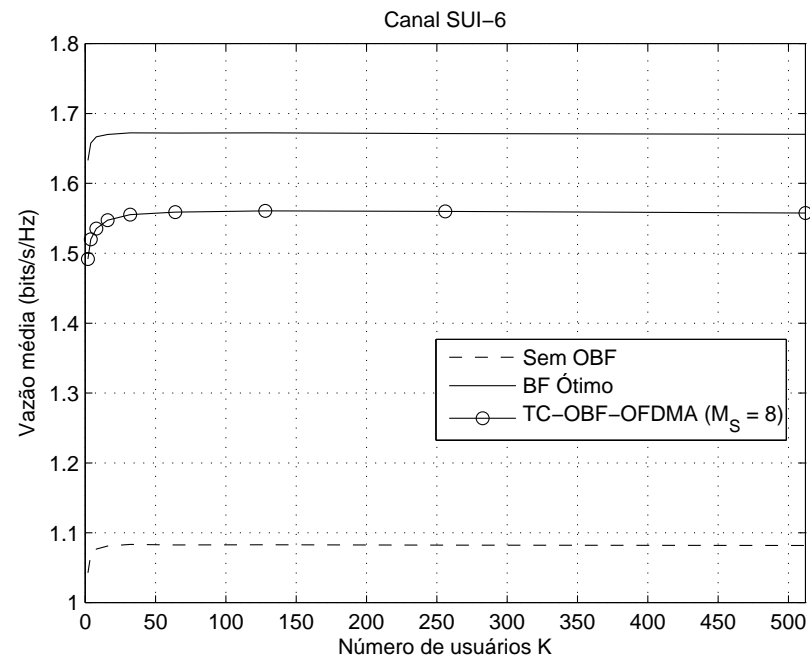

Fig. 4. Vazão média (bits/s/Hz) em função do número de usuários $K$, para um sistema com $N_{c}=128$ subportadoras, tamanho de memória $M=8$, tempo de latência $t_{c}=100$ e usuários com velocidade de 3 $\mathrm{Km} / \mathrm{h}$, considerando-se o modelo de canal SUI-6.

[2] P. Viswanath, D. N. C. Tse e R. Laroia, "Opportunistic beamforming using dumb antennas," IEEE Trans. Inform. Theory, v. 48, no. 6, pp. 1277-1294, Junho 2002.

[3] I. R. Baran, B. F. Uchôa-Filho, " Exploiting time coherence in opportunistic beamforming for slow fading channels," IEEE WCNC'06, v. 3, pp. 1753-1758, Maio 2006

[4] P. Svedman, L. J. Cimini, M. Bengtsson, S. K. Wilson e B. Ottersten, "Exploiting temporal channel correlation in opportunistic SDOFDMA," IEEE ICC'06, v. 12, pp. 5307-5312, Junho 2006.

[5] R. Laroia, J. Li, S. Rangan e M. Srinivasan, "Enhanced oportunistic beamforming," IEEE VTC'03 (Fall), v. 3, pp. 1762-1766, Outubro 2003.

[6] IEEE 802.16e, Air interface for fixed and mobile broadband wireless access systems, Fevereiro 2006.

[7] E. Dahlman, S. Parkvall, J. Skold e P. Beming, $3 G$ Evolution HSPA and LTE for Mobile Broadband, Academic Press, 2007.

[8] J. Hoadley e A. Javed, " Overview: Technology innovation for wireless broadband access," Nortel Technical Journal, no. 2, Julho 2005.

[9] C. Cordeiro, K. Challapali e D. Birru, "IEEE 802.22: An introduction to the first wireless standard based on cognitive radios," Journal of Commun., v. 1, no. 1, Abril 2006.

[10] H.Yaghoobi, "Scalable OFDMA physical layer in IEEE 802.16 wirelessMAN," Intel Technology Journal, v. 8, no. 3, pp 201-212, Agosto 2004. 